\title{
CELLULOSE ACETATE PRODUCTION BY ACETYLATION OF CELLULOSE DERIVED FROM DATE PALM FRONDS
}
A.S. Jassem*
Researcher
Sh. K. Muallah*
Asst.Prof.
A. H.Mohammed**
Lecturer

* Dept. Biochemical Eng. Coll. Al-Khwarizmi Eng. University. Baghdad

** Dept. Chemical Industries. Inst. Technology Baghdad. University. Middle technical

Ayat.ayo58@yahoo.com

\section{ABSTRUCT}

Cellulose acetate (CA) is a biopolymer produced from fronds of date palm (type teperzal) which were taken from the Iraqi groves. The steps used to produce (CA); pretreatment, bleaching, acetylation and hydrolysis. Organosolv pretreatment method was used to remove high lignin content under mild and severe conditions using $\mathrm{NaOH}$ as a catalyst at the concentration $(0.03)$ M. The conditions of Organosolv pretreatment were used: temperature $\left(125{ }^{\circ} \mathrm{C}\right.$ mild, $160{ }^{\circ} \mathrm{C}$ severe), pretreatment time 90 min, and ethanol: water ratio 40:60 wt/wt. The acetylation of cellulose with acetic acid was used to produce cellulose tri-(CTA) and di-(CDA) acetate for two ways: with treated and untreated fronds. The conditions of acetylation reaction were used: temperature $(50-55){ }^{\circ} \mathrm{C}$ and time $(1,2 \& 3) \mathrm{h}$. The product was characterized by the solubility test, titration method and Fourier transform infrared spectroscopy (FTIR). The results showed that the high percentage of lignin removed was $(93 \%)$, the best degree of substitution (DS) for (CTA) and (CDA) were 3.01 and 2.60. As well as the excellent solubility percentages for (CTA) with chloroform and mixture of chloroform/methanol were $90 \%$ and $84 \%$, respectively. While the solubility percentage for (CDA) with acetone was $95 \%$, these result occurred at pretreatment temperature $160^{\circ} \mathrm{C}$, pretreatment time 90 min and reaction time $3 \mathrm{~h}$.

Keywords: acetylation reaction, cellulose acetate, organosolv delignification, degree of substitution.

جاسم و آخرون مجلة العلوم الزراعية العراقية -975-967:51:2020 (3)

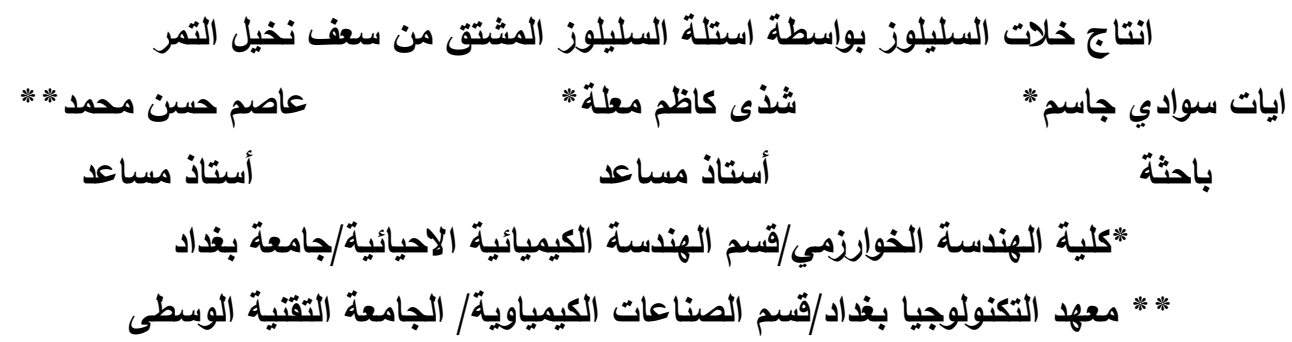

المستخلص

خلات السليلوز هو بوليمر حيوي تم إنتاجه من سعف نخيل التمر (نوع تبرزل) الذي تم أخذه من بساتين العرق. الخطوات المستخدمة

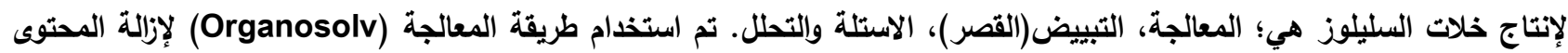
العالي من اللجنين في ظل ظروف معتلة وثديدة باستخدام هيدروكسيد الصوديوم كعامل مساعد عند تركيز (0.03) مول لكل لتر.

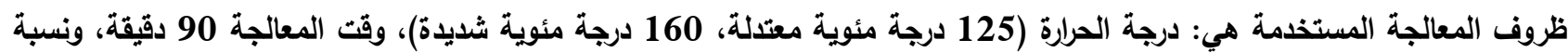

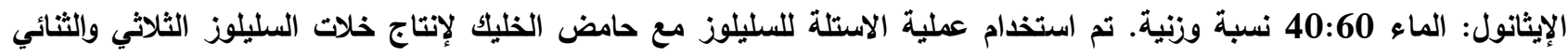

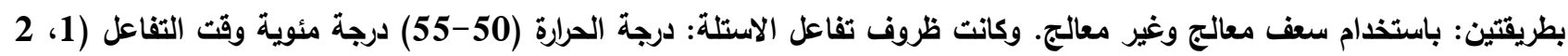
و3) ساعة. وتم اختبار المنتج باستخدام عدة طرق وهي: قابلية الذويان وطريقة التسحيح وجهاز (FTIR) وأظهرت النتائج أن نسبة عالية من اللنين التي تمت إزالتها كانت (93\%)، وأفضل درجة استبال (DS) لخلات السليلوز الثلاثي والثنائي كانت 3.01 و 2.60، وكانت

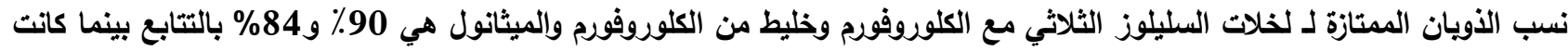

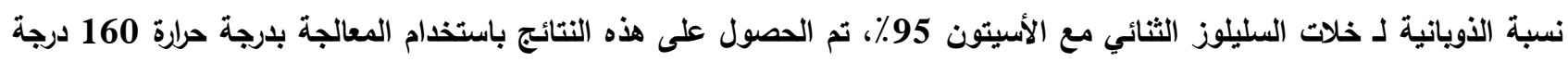
مئوية ويزمن 90 دقيقة و زمن تفاعل 3 ساعة. الكلمات المفتاحية: تفاعل الاستلة، سليلوز، خلات السليلوز، إزالة اللكنين بالمذيبات العضوية، درجة الاستبدال. 


\section{INTRODUCTION}

Cellulose acetate $(\mathrm{CA})\left[\mathrm{C}_{6} \mathrm{H}_{7} \mathrm{O}_{2}(\mathrm{OH}) 3-\mathrm{m}\right.$ $\left.\left(\mathrm{OOCCH}_{3}\right) \mathrm{m}\right], \mathrm{m}=0 \sim 3$, is the essential organic ester of cellulose due to it's a broad commercial and industrial importance. There are several applications of (CA): Textile and plastic industries $(10,25)$, camera accessories, thermoplastic moulding, magnetic tapes, photographic films, combs, electrical parts and telephone (14). Figure 1, shows that the most common types of cellulose acetate include cellulose diacetate, their degree of substitution (DS) ranging from 2-2.5 (6), and cellulose triacetate having the DS above 2.8 (11). The crystallinity and biodegradation in (CA) decrease according to the following order: cellulose triacetate, cellulose diacetate, and cellulose monoacetate (7). The acetyl content and DS heavily affect the quality of (CA) because it can affect the product and its solubility in the solvent. Currently, different types of cellulose derivatives, for instance, methyl cellulose, ethyl cellulose, carboxyl methyl cellulose, and cellulose acetate have been produced to change the chemical and physical properties of cellulose (10). Nowadays, acetylated wood is a commercial product in Europe (4). Generally, (CA) is prepared from raw cellulose, wood pulp, or agricultural waste materials. These materials include cotton by-products, sugar cane baggage, banana byproducts, wheat, and rice straw, and other materials have high cellulose content. Preparation of cellulose derivatives from these materials is an environmentally friendly and economically profitable approach (8).
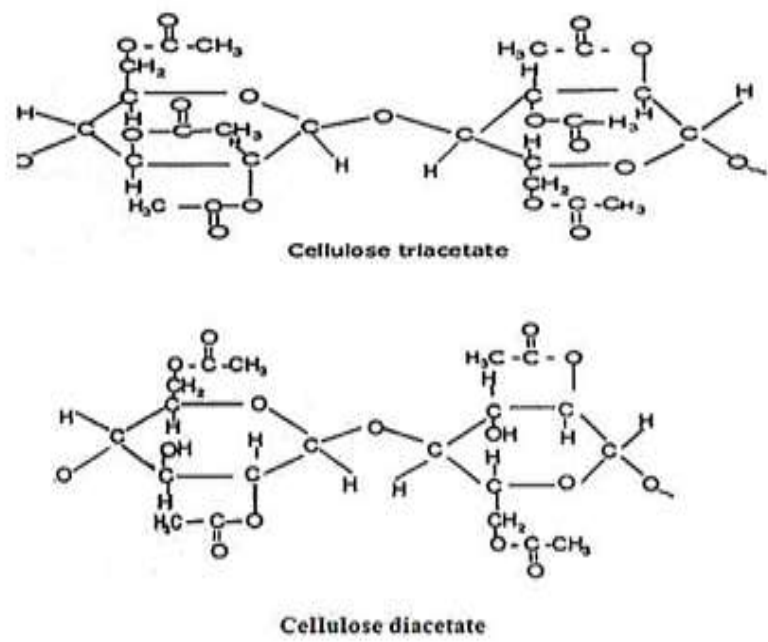

Figure 1. The structure of cellulose Tri- and Diacetate (6).
Fronds of the date palm as a suitable candidate for production of cellulose derivative for two reasons: The abundance of date palm trees and the fronds contain high cellulose percent nearly $42 \%$, which is essential for the production of (CA). Fronds of the date palm are lignocellulosic materials consist of hemicellulose, cellulose and lignin, which an abundant, nonfood and inexpensive biomass that represents a renewable and appropriate source of cellulosic fibers suitable for the synthesis of biopolymer (15). Additionally, hemicellulose and lignin should be removed from biomass because these two components have a negative effect on acetylation efficiency, as well as on the properties of the product (19). Acetylation reaction used in produced (CA), which are classified as heterogeneous and homogeneous acetylation. (CA) obtained from heterogeneous acetylation is more crystalline than from the homogeneous process. The hydrophilic hydroxyl groups of cellulose in the cell walls of the wood and the intercellular regions convert to a hydrophobic group in acetylation reaction (20). Commercially, cellulose is acetylated by adding acetic anhydride, glacial acetic acid, and various catalysts Such as pyridine, dimethyl amino pyridine, potassium acetate, and sulphuric acid to increase the rate of acetylation reaction. Production of (CA) needs a different time of acetylation based on cellulose sources to obtain suitable acetyl content. As time increase, (DS) and solubility of (CA) produced increase. Several types of research carried out about the production of (CA) such as microbial cellulose takes 5-10 $\mathrm{hr}$., bacterial cellulose from pineapple waste for $2 \mathrm{hr}$., straw for 2-3 hr. (3). The main objective of the research is to produce cellulose acetates from date palm fronds and determining the exact time required for cellulose acetylation.

\section{MATERIALS AND METHODS}

Fronds of date palm type (teperzal) were used and collected from Baghdad garden in Iraq. Impurities should be removed by washing the fronds then dried in sunlight. The dried materials were cut using electric cutter, crushed with humor and sieved with a particle size of (90-270) $\mu \mathrm{m}$ were selected for production a biopolymer (21). The chemicals 
used in the experimental work are: Ethanol, methanol, sodium hydroxide, hydrochloric acid, glacial acetic acid, acetic anhydride, sulphuric acid, acetone, hydrogen peroxide \& chloroform, all chemicals were obtained from LTD, India. The steps used in this research are:

\section{First: Compositional analysis of date palm fronds}

The composition of fronds or other resources of lignocellulosic materials is changed according to; the part of the plant from which the sample is taken, the place and growing season $(1,18)$. The percentage of extractives, moisture, ash, lignin, cellulose, Holocellulose, and hemicellulose content were investigated according to Ramsden and Blake (20) and A.Sluiter et al.,(21).

\section{Second: Pretreatment (delignification process)}

The purpose of pretreatment to increase the accessibility of the reagent, acetic anhydride to all the hydroxyl groups of cellulose, and to eliminate the non-cellulosic components such as hemicellulose and lignin (19).

Organosolv method: Different techniques of pretreatment of lignocellulosic materials were used, including pyrolysis, biological treatment, and alkaline hydrolysis, etc. (12). In this study, organic solvent (Organosolv) pretreatment was used to remove the high content of lignin from fronds. In this process, the lignocellulosic material is treated with ethanol or other solvents at rising temperature using water as a co-solvent in stainless steel reactor (digester) with a catalyst $\mathrm{NaOH}$. A mixture of biomass (fronds)-water-ethanol was made $(200 \mathrm{ml}$ solvent per $10 \mathrm{~g}$ biomass) to hydrolyze cellulose and hemicellulose. However, the main goals include the removal of lignin from the fronds and disruption of the crystalline structure of cellulose (16). This mixture was heated in the range $\left(125-160^{\circ} \mathrm{c}\right)$ and stirred for $90 \mathrm{~min}$. After filtration of the slurry, the remaining part was washed and then dried.

\section{Bleaching process}

The bleaching process is a chemical process used in several kinds of wood pulp to change the color of the pulp from brown to white and to remove the remaining lignin (8). In this process, the dried material was suspended in a $\mathrm{NaOH}$ solution with $30 \% \mathrm{H}_{2} \mathrm{O}_{2}$ at $\mathrm{pH} 12.0$ and placed in a hot water bath at $90^{\circ} \mathrm{C}$ for $60 \mathrm{~min}$ (10). After bleaching completed, a large amount of water is required for washing the residual hydrogen peroxide and the residual alkali then dried (13).

\section{Third: Cellulose acetylation}

\section{Production of cellulose triacetate (CTA)}

The acetylation of cellulose for the production of cellulose Triacetate includes three steps:

The activation of cellulose was done by mixing $60 \mathrm{~mL}$ of acetic acid glacial, $0.4 \mathrm{~mL}$ of sulphuric acid (95\% concentration) and $4 \mathrm{~g}$ of the bleached stalk. The system was put in a water bath at (50-55) ${ }^{\circ} \mathrm{C}$ for $1 \mathrm{~h}$., with frequent stirring.

a- The acetylating mixture consisting of $20 \mathrm{~mL}$ acetic anhydride, $10 \mathrm{~mL}$ acetic acid glacial, and $0.6 \mathrm{~mL}$ of $\mathrm{H}_{2} \mathrm{SO}_{4}$ added to the above mixture, which is placed in a water bath for 1 , 2 and $3 \mathrm{~h}$., with stirring till a clear solution obtained

b- The solution divided into two equal parts. The first portion was used for cellulose triacetate production by carefully pouring into a large volume of water. Finally, Cellulose triacetate formed as a precipitate. The precipitate was filtered and washed to neutrality and dried. The second portion was used for production of cellulose diacetate (2).

\section{Production of cellulose diacetate (CDA)}

$=$ The hydrolysis process of (CTA) produced (CDA). The reaction involves the use of water as the main reactant and acids as catalyst (10). Hydrolysis is the opposite of the acetylation process where the sometimes unavoidable excess of the $\mathrm{OH}$ group by the acetyl group gives a high degree of substitution, which can be repaired. Hydrolysis helps in decreasing DS of cellulose acetate from three acetyl groups per cellulose to two acetyl groups in the range of (2.4-2.5).

This process includes:

a- Mixture of $24 \mathrm{~mL}$ of acetic acid glacial and $7 \mathrm{~mL}$ of water added to the second portion of the mixture obtained from acetylation reaction, with strong stirring to avoid precipitation, and it was allowed to stand for $1 \mathrm{~h}$ at (50-55) ${ }^{\circ} \mathrm{c}$.

b- The mixture poured into a large volume of water, and the cellulose diacetate formed as a precipitate. The product was filtered and washed to neutrality and dried (2). 
Forth: Characterization of the cellulose acetates

CTA and CDA can be characterize by:

\section{Degree of substitution (DS)}

The degree of substitution is an essential parameter for the transformation of cellulose into cellulose acetate, and it was controlled by time of acetylation reaction. The most common method for determined (DS) is a titration method. This method based on the hydrolysis of ester bonds in the alkali solution (22). (DS) can be calculated as follow: $0.5 \mathrm{~g}$ of cellulose acetate and $20 \mathrm{~mL}$ of $(75 \%$ concentration) ethanol heated to $55^{\circ} \mathrm{C}$ for $1 \mathrm{~h}$ for better swelling of the sample. $20 \mathrm{~mL}$ of 0.5 mole/ $\mathrm{L} \mathrm{NaOH}$ solutions added to each sample, and the mixture also heated at $55^{\circ} \mathrm{C}$ for $1 \mathrm{~h}$. These procedures also applied for cellulose (control). The mixture stayed at a laboratory temperature for $72 \mathrm{~h}$. The excess sodium hydroxide in the samples and control titrated with 0.5 mole/ $\mathrm{L} \mathrm{HCl}$ using phenolphthalein as an indicator. $0.5 \mathrm{~mL}$ of acid was added and the $\mathrm{NaOH}$ was permitted to diffuse for $24 \mathrm{~h}$. after that, small amount of acid was then also titrated with $0.5 \mathrm{~mole} / \mathrm{L} \mathrm{NaOH}$ until the solution had acquired a faint pink color $(23,17)$. The acetyl content (A\%) was calculated according to equation [1]:

$$
A \%=[(D-C) N a+(A-B) N b] *\left(\frac{4.305}{W}\right) \ldots[1]
$$

Where:

$\mathrm{A} \& \mathrm{~B}=$ the volumes $(\mathrm{mL})$ of $\mathrm{NaOH}$ required for the titration of the sample and blank respectively

$\mathrm{C} \& \mathrm{D}=$ the volumes $(\mathrm{mL})$ of $\mathrm{HCl}$ required for the titration of the sample and blank respectively

$\mathrm{N}_{\mathrm{a}} \& \mathrm{~N}_{\mathrm{b}}=$ the normality of $\mathrm{HCl}$ and $\mathrm{NaOH}$ respectively

$\mathrm{W}=$ the mass of the CA sample used. The ( \% A) obtained from equation [1] was used to calculate the DS according to equation [2] (9).

$$
D S=\frac{162 * A \%}{4305-43 * A \%}
$$

\section{Solubility test}

One of the means of biopolymer identification is solubility test. The solubility will give an indication for the type of cellulose acetate. In this test, cellulose tri and diacetate are put in solvents: acetone, chloroform and mixture of chloroform/methanol in ratio $(9: 1 \mathrm{v} / \mathrm{v})$ for a certain time with stirring at laboratory temperature (10). The solubility percentage was calculated according to equation [3] solubility $\%=\frac{M 1-M 2}{M 1} \quad \ldots . .[3]$

Where:

$\mathrm{M}_{1}=$ total mass of cellulose acetate

$\mathrm{M}_{2}=$ mass of insoluble cellulose acetate

Fourier Transform Infrared (FTIR)

The functional groups of cellulose, cellulose tri- and di- acetate studied by using (FTIR) apparatus. The disc was prepared by mixing and compressing the sample with Potassium bromide at a ratio 1:1. The wavelength range from 450 to $4000 \mathrm{~cm}^{-1}$ (3).

\section{RESULTS AND DISCUSSION}

The results are divided into four parts. The first part deals with the results of the compositional analysis of the fronds. The second part is relates to the results of Organosolv method. The third part concerned with the results of acetylation reaction of cellulose by two ways; using treated and untreated fronds. While the last part deals with the study of the results of cellulose acetate characterization.

Compositional analysis of date palm fronds The compositions of date palm fronds were determined as show in (Table 1).

Table 1. The compositions of date palm fronds based on dry weigh

\begin{tabular}{|cc|}
\hline Weigh $\%$, based on (dry basis) \\
\hline Cellulose & 42 \\
Hemicellulose & 18 \\
Lignin & 25 \\
Extractive & 8 \\
Ash & 7 \\
\hline
\end{tabular}

From Table 1, there is a relatively high percentage of cellulose in date palm fronds; this enhances the possibility of producing cellulose acetate.

\section{Pretreatment (delignification process)}

In this research, Organosolv and bleaching methods used for the delignification of fronds. These processes aim to remove lignin content and hemicellulose in the range of temperature (125-160) ${ }^{\circ} \mathrm{C}$ in stainless steel reactor of pretreatment time 90 min with a catalyst $(0.03$ M) $\mathrm{NaOH}$. Composition of fronds determined after delignification process, as shows in the Table 2 and found that the minimum lignin percent was $10.31 \%$ and $6 \%$ which obtained at temperature $125^{\circ} \mathrm{C}$ and $160^{\circ} \mathrm{C}$ respectively, thus the best removal of lignin content at a temperature $160^{\circ} \mathrm{C}$. 
Table 2. The compositions of date palm fronds after delignification processes

\begin{tabular}{|lccccc|}
\hline \multicolumn{5}{c|}{ Weight \%, based on (dry basis ) } \\
\hline Sample & cellulose & hemicellulose & lignin & extractive & ash \\
At $125^{\circ} \mathrm{c}$ & 65 & 9.9 & 10.31 & 3.89 & 10.9 \\
At $160^{\circ} \mathrm{c}$ & 78 & 4 & 6 & ----- & 11 \\
\hline
\end{tabular}

Production of cellulose tri- and di-acetate

Production of cellulose acetate includes several stages; activation, acetylation, hydrolysis, precipitation, and drying, respectively. Glacial acetic acid used as an activator and sulphuric acid as a catalyst in an activation process to increase cellulose surface area and decrease the intermolecular hydrogen bonds. For the facilitating acetylation process, acetic anhydride used as a reagent. Cellulose tri- and di-acetate produced in two ways: treated and untreated fronds. Acetylation of Cellulose caused by oxidative changes of cellulose molecules and change the color from white to brown. After the reaction was completed, cellulose triacetate formed but cellulose diacetate produced after hydrolysis process of cellulose triacetate with acetic acid. Cellulose acetate produced from treated fronds was white powder, while the shape of cellulose acetate produced from untreated fronds was a brown powder because of the presence of lignin which effect on the reaction efficiency and on the characteristic of cellulose acetate produced.

\section{Characterization of the cellulose tri- and di-} acetate

Degree of substitution (DS): The DS for cellulose tri- and di-acetate was determined by the titration method with an aqueous solution of $\mathrm{NaOH}$. The amount of obtaining acetyl content for cellulose tri- and di-acetate is dependent on the duration of acetylation reaction and the lignin percent. Figure (2A) shows that the DS value for CTA and CDA increased With time of acetylation reaction but the value of DS is very low due to the presence of a high percentage of lignin in the sample that binds the cellulose molecule and prevents the breakdown of hydrogen bonds. Thus, accessibility of acetic anhydride to hydroxyl group is too weak and consequently a partial transformation of cellulose-to-cellulose acetate occur. In figure (2B), the value of the DS is slightly higher than in figure (2A) due to use of $\mathrm{NaOH}$ catalyst in the pretreatment of sample at $125^{\circ} \mathrm{C}$ that remove high percent of lignin. While in figure $(2 \mathrm{C})$ it was found that when the sample was treated at high temperature of $160{ }^{\circ} \mathrm{C}$, very high DS was obtained since a maximum decrease in the amount of lignin obtained, as a result completely acetylation of cellulose was occurred to form CTA and CDA. The high value Of DS shows a high hydroxyl substitution in the cellulose molecule by the acetyl group
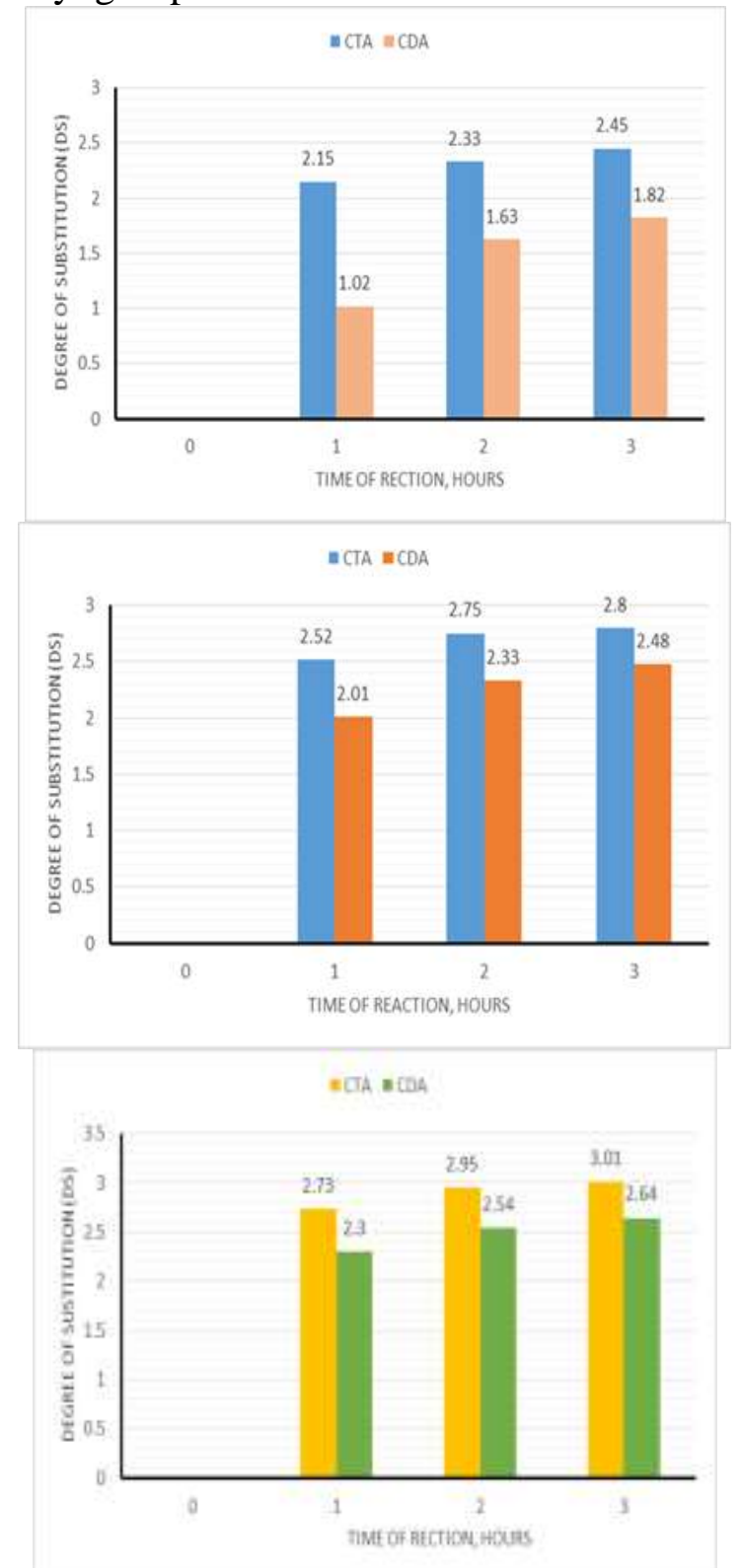

Figure 2. Effect of acetylation time and pretreatment on the DS of CTA and CDA for (A) untreated sample, (B) sample treated at $125^{\circ} \mathrm{C}$, and (C) sample treated at $160^{\circ} \mathrm{C}$. 


\section{Solubility test}

The solubility of cellulose acetate depends on the average degree of substitution (DS) and lignin content. The solubility test for the resultant product indicated that cellulose triacetate was soluble in chloroform and

Table 3. The solubility test of cellulose tri- and di-acetate for acetylation time $3 \mathrm{~h}$

Acetone \%
insoluble
$53 \%$
Acetone \%
insoluble
$95 \%$

Acetone \% insoluble $82 \%$
Chloroform \%

$49 \%$

insoluble

Chloroform \%
$90 \%$
insoluble

Chloroform \% $80 \%$ insoluble
Chloroform/methanol (9:1) \% $44 \%$

insoluble
Chloroform/methanol (9:1) \% $84 \%$ insoluble

Chloroform/methanol (9:1) \% $72 \%$ insoluble

cellulose diacetate

the result of FTIR analysis of the cellulose triacetate showed that the intensity in the band of the O-H group decreased significantly, meaning that fully acetylated was occurred that all $\mathrm{O}-\mathrm{H}$ group was substituted by the acetyl group. Other groups such as the $\mathrm{C}-\mathrm{H}$ group was showed at $2962.66 \mathrm{~cm}-1$ and the carbonyl group $\mathrm{C}=\mathrm{O}$ was observed at 1750 $\mathrm{cm}-1$. While in Figure $(\mathrm{C})$, the result for cellulose diacetate showed that the intensity of $\mathrm{O}-\mathrm{H}$ groups at $3568.31 \mathrm{~cm}-1$ decreased slightly. A strong band of carbonyl group $\mathrm{C}=\mathrm{O}$ was observed at $1769.51 \mathrm{~cm}-1$. This indicates that some of the $\mathrm{O}-\mathrm{H}$ groups in the cellulose have been substituted by the acetyl group and incompletely acetylated has occurred to form cellulose diacetate. On the other hand, the ether groups $\mathrm{C}-\mathrm{O}$ were also showed at 1224 $\mathrm{cm}-1$ and $\mathrm{C}-\mathrm{H}$ groups at $2962.66 \mathrm{~cm}-1$. The carbonyl groups $\mathrm{C}=\mathrm{O}$ make up the cellulose tri- and di-acetate. The FTIR spectra were established that the acetylation process of cellulose into cellulose tri- and di-acetates had been successfully carried out. 


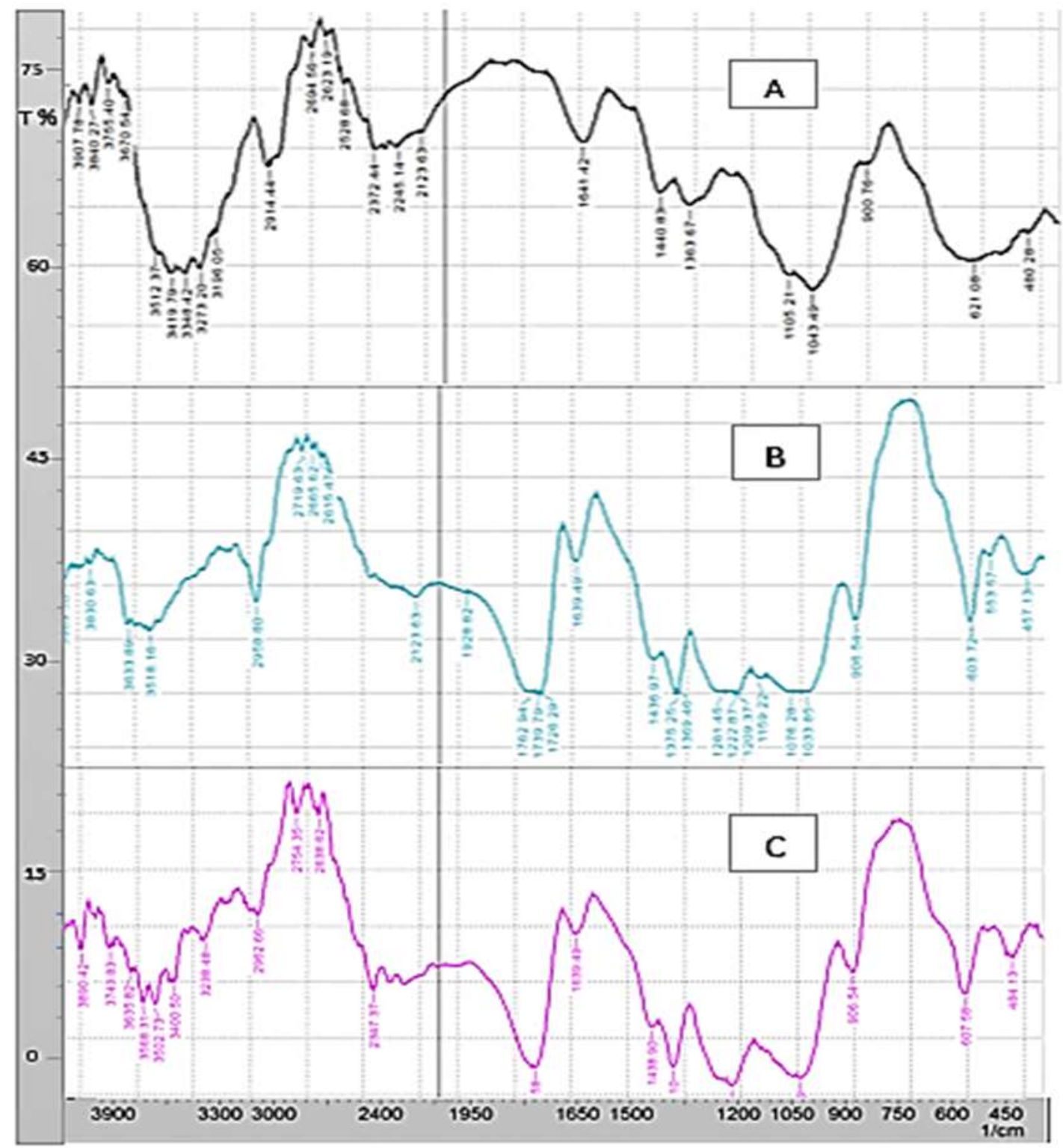

Figure 3. FTIR Analysis of (A) cellulose, (B) cellulose triacetate, and (C) cellulose diacetate

\section{CONCLUSION}

In this research, compositional analysis of fronds, pretreatment and preparation of pulp from fronds, cellulose acetylation and cellulose acetates production has been achieved. However, this study has shown that they can be used an agricultural raw material (date palm fronds) for the production of pulp, and cellulose biopolymers (cellulose tri- and di-acetate). The reaction conditions required for converting the fronds powder to cellulose acetate was established. The production of cellulose acetate from untreated fronds is not preferred method because of its low solubility and low degree of substitution. It was found that the acetylation time of $2 \mathrm{~h}$, pretreatment time $90 \mathrm{~min}$ and pretreatment temperature 165 ${ }^{\circ} \mathrm{C}$ was sufficient to obtain cellulose tri- and di-acetate with high solubility and high degree of substitution. It can be concluded that the lignin content has negative effect on the following: first, it consumes more acetic anhydride because all component will be acetylated. Second, lignin is considered a barrier to prevent the acetylation process of a hydroxyl group. Third, acetylated lignin effect on the DS and the dissolution of cellulose triand di-acetate. Therefore, fronds of date palm can be delignified by using modified Organosolv method in which the lignin is damaged by solvent and high temperature. The prepared cellulose acetates are characterized by FTIR spectroscopy, solubility test, and titration method.

\section{REFFERENCES}

1. Alananbeh K. M., N. A. Bouqellah and N. S. Al Kaff. 2014. Cultivation of oyster mushroom Pleurotus ostreatus on date-palm 
leaves mixed with other agro-wastes in Saudi Arabia. Saudi Journal of Biological Sciences. King Saud University, 21(6): 16-25

2. Akpabio U. D., I. E. Effiong and A. E. Akpakpan. 2012. Preparation of pulp and cellulose acetate from nypa palm leaves. International Journal of Environment and Bioenergy, 1(3): 179-194

3. Bahmid N. A., K. Syamsu and A. Maddu. 2013. Production of cellulose acetate from oil palm empty fruit bunches cellulose. Chemical and Process Engineering Research, 17(21): 1220

4. Cetin N. S., and N. Ozmen. 2011. Acetylation of wood components and fourier transform infrared spectroscopy studies. African Journal of Biotechnology, 10(16): 3091-3096

5. Djuned F. M., M. Asad, M.N. M. Ibrahim and W. R. W. Daud. 2014. Synthesis and characterization of cellulose acetate from TCF oil palm empty fruit bunch pulp. BioResources, 9(3): 4710-4721

6. Fischer S., K. Thummler, B. Volkert, K. Hettrich, I. Schmidt and K. Fischer. 2008. Properties and applications of cellulose acetate. Macromolecular Symposia, 262(1): 89-96

7. Filho G. R., R. C. D. Silva, C. D. S Meireles, R. M. N. D. Assunc and H.Otaguro. 2004. Water flux through blends from waste materials: Cellulose acetate (from sugar cane bagasse) with polystyrene (from plastic cups). Journal of Applied Polymer Science, 96: 516522

8. Fornell R. 2012. Process Integration Studies on Kraft Pulp-Mill-Based Biorefineries Producing Ethanol. thesis, pp: 1-83

9. Fei P., L. Liao, B. Cheng and J. Song. 2017. Quantitative analysis of cellulose acetate with a high degree of substitution by FTIR and its application. Analytical Methods, 9(43): 61946201

10. Gopinath B. K. K. and Y. Jahai. 2015. Synthesis of commercially valuable cellulose acetate from agriculture waste. International Journal of Multidisciplinary advanced research trends, 2(1): 1-6

11. Heinze T., T. F. Liebert, K. S. Pfeiffer and M. A. Hussain. 2003. Unconventional cellulose esters: synthesis, characterization and structure property relations. Springer, 10(3): 283-296

12. Harmsen P.F.H., W.J.J. Huijgen, L.M. B. López and R.R.C. Bakker. 2010. Literature review of treatment processes for biomass. Food and biobased research (September), 1-49 13. Hashem M., M. El-Bisi, S. Sharaf and R. Refaie. 2010. Pre-cationization of cotton fabrics: An effective alternative tool for activation of hydrogen peroxide bleaching process. Carbohydrate Polymers, 79(3): 533540

14. Israel A.U., I.B. Obot, S. A. Umoren, V. Mkpenie and J.E. Asuquo. 2008. Production of cellulosic polymers from agricultural waste. EJournal of Chemistry, 5(1): 81-85

15. Khatami M. and S. pourseyedi. 2015. Phoenix dactylifera (date palm) pit aqueous extract mediated novel route for synthesis high stable silver nanoparticles with high antifungal and antibacterial activity. IET nanobiotechnologh, 9(4): 90-184

16. Kumar P., D. M. Barrett, M. J. Delwiche, and P. Stroeve. 2009. Methods for pretreatment of lignocellulosic biomass for efficient hydrolysis and biofuel production. Industrial and Engineering Chemistry Research, 48(8): 3713-3729

17. Kim D. Y., Y. Nishiyama and S. Kuga. 2002. Surface acetylation of bacterial cellulose. Entomologia Experimentalis ET Applicata, 103(3): 239-248

18. Mahdi Y. S., A. K. Mohammed and A. H. Mohammed. 2018. Synthesis of rayon from date palm fronds. Iraqi Journal of Agricultural Sciences, 49(6):1049-1059

19. Gilbert M. S. and I. Palle. 2013. Cellulose acetate production from Acacia mangium pulp. Fourth International Conference on Biology. Malaysia, 100: 118-123

20. Ramsden M. J. and F. S. R. Blake. 1997. A kinetic study of the acetylation of cellulose, hemicellulose and lignin components in wood. Springer, 31(October 1995):45-50

21. Sluiter A., B. Hames, R. Ruiz, C. Scarlata, J. Sluiter, D. Templeton, and D. Crocker. 2012. Technical Report NREL/ TP -510 42618: $1-15$

22. Senna A. M., K. M. Novak, J. B. D Carmo, and V. R. Botaro. 2014. Synthesis and characterization of hydrogels from cellulose acetate by esterification crosslinking with 
EDTA dianhydride. Carbohydrate Polymers 114: $260-268$

23. Samios E., R. K. Dart and J. V. Dawkins. 1997. Preparation, characterization and biodegradation studies on cellulose acetates with varying degrees of substitution. Polymer, 38(12): 3045-3054

24. Yan L., W. Li, Z. Qi and S. Liu. 2006. Solvent-free synthesis of cellulose acetate by solid super acid catalysis. Journal of Polymer Research, 13(5): 375-378. 